\title{
Formação, currículo discurso político
}

\author{
Formation, curriculum, political discourse \\ Formación, discurso político curricular
}

MARIA CECÍLIA DE SOUZA MINAYO
Orcid Id: https://orcid.org/0000-0001-6187-9301
Universidade Federal do Rio de Janeiro

PEDRO DEMO

Orcid ld: https://orcid.org/0000-0002-5514-2781

Universidade de Brasília

RENAN ANTÔNIO DA SILVA

Orcid Id: https://orcid.org/0000-0003-1171-217X

Universidade de Mogi das Cruzes

Resumo: Neste artigo apresenta-se uma discussão sobre currículos e programas em educação profissional em que se consideram aspectos culturais, educação formal e não formal. Trata de questões suscitadas em sala de aula, ao longo do desenvolvimento de uma disciplina sobre Currículos e Programas, ministrada em um programa de pós-graduação profissional. O objetivo deste artigo foi o de discutir os diferentes entendimentos e avanços anunciados para as questões curriculares com base na concepção das políticas atuais da educação brasileira, quanto à formação técnica e tecnológica; e analisar propostas de projetos transversais em práticas de extensão que apresentam características da educação não formal. A metodologia, de abordagem qualitativa, trata da descrição de projetos desenvolvidos em diferentes unidades de ensino (UEs) de uma instituição pública de educação técnica e tecnológica de São Paulo, a partir de um estudo sobre práticas de extensão. Como resultado, apresenta-se uma discussão sobre uma prática de responsabilidade social e educação não formal no currículo de ensino superior tecnológico.

Palavras-chave: Cultura; Discurso Político-Educacional; Extensão; Educação Profissional.

Abstract: This article presents a discussion about curriculum and programs in professional education in which they are considered cultural aspects, formal and non-formal education. It deals with questions raised in the classroom, throughout the development of a discipline on Curriculum and Programs, taught in a professional graduate program. The purpose of this article is to discuss the different understandings and advances announced for curriculum issues based on the conception of current Brazilian education policies, regarding technical and technological training; and analyze proposals for transversal projects in extension practices, which present characteristics of non-formal education. The methodology, with a qualitative approach, deals with the description of projects developed in different teaching units (UEs), of a public institution of technical and technological education in São Paulo, based on a study on extension practices. As a result, there is a discussion about the practice of social responsibility and non-formal education in the technological higher education curriculum.

Keywords: Culture; Political-Educational Discourse; Extension; Professional Education. 


\begin{abstract}
Resumen: Este articulo presenta una discusión sobre planes de estudio y programas en educación profesional que consideran aspectos culturales, educación formal y no formal. Se trata de cuestiones planteadas en el aula, a lo largo del desarrollo de una disciplina sobre planes de estudio y programas, que se imparte en un programa profesional de posgrado. El propósito de este artículo fue discutir los diferentes entendimientos y avances anunciados para temas curriculares basados en la concepción de las politicas educativas brasileñas actuales, con respecto a la capacitación técnica y tecnológica; y analizar propuestas de proyectos transversales en prácticas de extensión, que presentan características de la educación no formal. La metodología, con un enfoque cualitativo, aborda la descripción de proyectos desarrollados en diferentes unidades de enseñanza (UE), de una institución pública de educación técnica y tecnológica en São Paulo, basada en un estudio sobre prácticas de extensión. Como resultado, hay una discusión sobre una práctica de responsabilidad social y educación no formal en el plan de estudios tecnológico de educación superior.
\end{abstract}

Palabras clave: Cultura; Discurso politico-educativo; Extensión; Educación profesional.

\title{
INTRODUÇÃO
}

Em uma discussão sobre currículos e programas, não só em educação profissional, como também na educação regular, são relevantes as considerações sobre o contexto social e cultural em que se organiza um determinado projeto político-pedagógico de um curso. E na educação contemporânea, com as novas orientações político-educacionais para a educação profissional, é pertinente essa discussão sobre implicações sociais e culturais no currículo.

No atual quadro da educação brasileira, no que se refere à educação profissional, é relevante observar o discurso contemporâneo em relação ao contexto social e cultural, dadas as exigências do mundo do trabalho e a necessidade atual de interação por meio de diferentes linguagens e tecnologias. Segundo esse ponto de vista, a educação está presente na sociedade, enquanto experiência social, acadêmica e científica para se desenvolverem estratégias de interação social e profissional.

É necessário, portanto, considerar a educação profissional nesse novo cenário social brasileiro, no que se refere à cultura tecnológica e demandas do mundo do trabalho e às exigências da sociedade. A educação está em permanente estado de mudança, segundo Tedesco (1995), como expressão particular da crise do conjunto de instâncias da estrutura social, desde o mercado de trabalho, sistema administrativo até o sistema político, família e sistema de valores e crenças.

Nesta discussão sobre o currículo, são pertinentes as considerações de Tedesco (1995), sobre modos de produção, tecnologia, globalização e competência para conquistar mercados que modificam padrões de produção e organização do trabalho, em constante mudança, em que se atualiza o pensar. As exigências atuais necessitam da introdução da inteligência nas diversas fases do processo 
produtivo, o que justifica, também, o fato de constantes atualizações no currículo em programas de educação profissional tecnológica, inclusive no que se refere à responsabilidade social.

Segundo Tedesco (2002), na educação, é uma postura otimista acreditar que a mudança social poderia se efetivar, a partir do foco no conhecimento, na ideia de que o desenvolvimento cognitivo possa influenciar as condutas e o comportamento do indivíduo. Para esse autor, ensinar a pensar bem e melhor estava associado geralmente à ideia de se formar um ser mais humano. Ou mesmo enfoques interdisciplinares que permitiriam a compreensão da complexidade dos fenômenos e atuariam de maneira mais responsável e consciente.

Apesar de, para Tedesco (2002), esse otimismo ter sido rapidamente substituído por visões mais realistas e complexas, no que se refere aos efeitos democratizadores de novos padrões de organização social e econômica, baseados no conhecimento e na informação, a educação não formal, segundo Gohn (2006 a), um dos núcleos da Pedagogia Social, perpassa diversas dimensões do processo educativo, a fim de possibilitar aos sujeitos uma compreensão de sua realidade.

$\mathrm{Na}$ instituição estadual de educação profissional e tecnológica estudada em sala de aula, ao longo do desenvolvimento da disciplina Currículos e Programas, ministrada em um programa de pós-graduação profissional, desenvolve-se uma prática de extensão de responsabilidade social. Em algumas unidades de ensino dessa instituição, são propostos projetos transversais em diferentes cursos de tecnologias. Segundo Machado; Prados e Martino (2018), nesse sentido, e por meio da articulação de diferentes atividades curriculares, entende-se que uma instituição de ensino superior pode articular as esferas do ensino, da pesquisa e da extensão, esta última que, também, pode se caracterizar como responsabilidade social universitária, de modo a contribuir, entre outras questões, para a inclusão social e o desenvolvimento econômico e social em seu entorno, o que atende à Lei 10.861, de 14 de abril de 2004, em seu Art. $3^{\circ}$, Inciso III (BRASIL, 2004).

Assim, as ações de uma educação que tem como propósito uma formação para a cidadania transpõem os saberes do ensino formal. No desenvolvimento deste estudo proposto na disciplina Currículos e Programas, de um programa de pós-graduação em educação profissional, foram considerados projetos transversais desenvolvidos em diferentes unidades de ensino superior tecnológico de uma instituição pública estadual de educação tecnológica de São Paulo.

O objeto dessa análise foi um item de um Plano de Gestão, um documento encaminhado pelas unidades de ensino à administração central dessa instituição estudada. Os dados referentes ao Item III, "Responsabilidade social na inclusão 
e desenvolvimento socioeconômico-ambiental", descritos por Machado; Prados e Martino (2018), que juntamente a outros nove itens, compreendem o Anexo I, desta Portaria institucional (SÃO PAULO, 2013).

Assim, entre as ações de extensão, no que se refere ao compromisso de se atenderem às demandas sociais e do mundo do trabalho, em educação profissional, são desenvolvidos tais projetos transversais que se voltam ao contexto social e cultural, em que as unidades de ensino estão inseridas. E essa prática de extensão permite que a instituição de ensino se relacione para além de si mesma, que se abra ao seu entorno, à sociedade mais ampla, sem estabelecer-se uma relação de subordinação, mas sim de compartilhamento de saberes (SANTOS, 2011).

No desenvolvimento desta discussão, delineiam-se três etapas: a primeira, Concep̧ø̃os de Currículo e Diferentes Visões, descrevem-se algumas discussões conceituais desenvolvidas em sala de aula a partir de diferentes correntes sobre concepções de currículo; a segunda, Cultura, Direitos e o Currículo, em que se consideram aspectos sociais e culturais do currículo, responsabilidade social e educação não formal na formação superior tecnológica; a última, Projetos Transversais, Responsabilidade social na inclusão e desenvolvimento socioeconômico-ambiental, em que se descrevem projetos propostos em atendimento às demandas sociais e do mundo do trabalho, pelas unidades de ensino e constantes em seu Plano de Gestão.

\section{CONCEPÇÕES DE CURRÍCULO E DIFERENTES VISÕES}

Segundo Sacristan (2013), ao se estudar o currículo, em um primeiro momento tem-se uma ideia de que é simples, pois é traçado o que um aluno vai estudar, mas quando se desvelam todas as suas implicações e agentes envolvidos, tem-se uma gama de dimensões que envolvem dilemas e situações em que se exigirá um determinado posicionamento.

É fundamental a Sociologia do currículo, segundo Schmidt (2003), pois a contínua análise deste, segundo uma abordagem conceitual e histórica, considera a sua não neutralidade. O currículo não é um elemento inocente, nem de transmissão desinteressada do conhecimento social, que tem uma história que precisa ser estudada e compreendida, pois não é um elemento transcendental, nem atemporal. Segundo Schmidt,

a construção das conceituações de currículo são produções humanas que estão marcadas pelas opções valorativas realizadas em cada tempo e lugar, construindo a concepção curricular vigente, sempre com a ideia de que ela é a melhor para o contexto vivido (SCHMIDT, 2003, p.59). 
Segundo Sacristán (2013), o termo deriva do Latim, da palavra currículo, que tem a mesma raiz de cursos e currere. $\mathrm{O}$ termo era utilizado para significar carreira e seu sentido, portanto, determinava a ordenação e representação do percurso daquele cidadão que acumulava "honras", no desempenho de sucessivos cargos eletivos e judiciais. Atualmente, esse conceito derivou-se em dois sentidos, não se refere só ao percurso, ou ao decorrer da vida profissional e a seus êxitos (o que é denominado de curriculum vitae), mas também tem o sentido de constituir, de maneira mais concreta, a carreira do estudante e elencados conteúdos, sua organização, além daquilo que o aluno deverá aprender, superar e em que ordem deverá fazê-lo.

Originalmente, as enciclopédias, segundo Burke (2003), referiam-se ao currículo educacional. O autor aponta ainda que, no século XVII, caracterizavase o sistema de disciplinas na organização do conhecimento. O tripé intelectual, na prática cotidiana das universidades europeias, seria composto de currículos, bibliotecas e enciclopédias. Da organização dos currículos, no primeiro grau, o bacharelado compunha-se de duas partes, o trivium, mais elementar: Linguagem (gramática, lógica e retórica) e o quadrivium, mais avançado: Números (aritmética, geometria, astronomia e música). Assim, a criação da enciclopédia decorreu da organização desse conhecimento. Dessa ordem, portanto, disciplina e ensino (currículo) dava-se a organização da biblioteca, ou ordem dos livros.

A enciclopédia de Gregor Reisch, por exemplo, publicada pela primeira vez em 1502 e bastante reimpressa no século XVI, era dividida em 12 livros, resumindo os conteúdos do trivium, e quadrivium e da filosofia natural e moral. (BURKE, 2003, p.89)

Essas sete artes, segundo Sacristán (2013), constituíram uma primeira organização formal do conhecimento, que perdurou por séculos nas universidades europeias. Nessa organização, distinguem-se dois grupos de conhecimentos na orientação da formação de um indivíduo, um grupo que se refere ao modo como o indivíduo adquire conhecimento e aquele grupo, mais pragmático, voltado a como o indivíduo se sustenta (SACRISTÁN, 2013).

O conceito de currículo e o uso que se faz dele na educação formal, para Sacristán (2013), aparecem desde os primórdios relacionados à ideia de seleção de conteúdos e de ordem na classificação dos conhecimentos que representam a seleção daquilo que será coberto pela ação de ensinar. Desempenha a dupla função: organizadora e unificadora, do ensinar e do aprender, por um lado, e por outro, paradoxalmente, devido ao fato de que nele se reforçam as fronteiras que delimitam seus componentes, por exemplo, separação entre as disciplinas que o compõem. 
Assim, juntamente à ordenação do currículo, é regulado o conteúdo e são distribuídos os períodos para se ensinar e aprender, bem como, o que se aprende e sobre como é ensinado. Além disso, separa-se o que se constitui como conteúdo e o que se considera que este seja inserido e, mesmo, conteúdos externos ou estranhos. Também, delimitam-se os campos das disciplinas e especialidades, além das delimitações das referências para a composição do currículo e de uma orientação para prática de seu desenvolvimento (SACRISTÁN, 2013).

Outras concepções sobre o currículo, influenciadas pela teoria social europeia, pela psicanálise e por Paulo Freire, segundo Schmidt (2003), constituem uma tendência curricular crítica, pois se opõem à abordagem técnica do currículo e dão ênfase ao caráter político de processos do pensar e fazer currículo, ao se voltarem para a prática e conhecimento escolar.

Segundo Young (2014), no currículo, o conhecimento é especializado, geralmente, organizado para ser transmitido de uma geração à outra. E é essa ideia sobre conhecimento e currículo que deveria possibilitar a análise e a crítica de suas diferentes formas para se propor novas alternativas.

O conhecimento no currículo, para Young (2014), é sempre conhecimento especializado de duas maneiras: a primeira, em relação às fontes disciplinares, como o conhecimento produzido por especialistas nas diferentes áreas; a segunda, em relação a diferentes grupos de aprendizes, ou seja, o currículo é elaborado para grupos específicos de aprendizes e está subordinado ao conhecimento anterior de que tais grupos dispõem.

Embora o propósito dos especialistas seja a busca da verdade, nem sempre concordam ou acertam, pois, às vezes, são influenciados por outros fatores, além da busca da verdade. É difícil pensar, no entanto, em uma fonte mais confiável para "o melhor conhecimento disponível” em qualquer campo. "Não há país com um bom sistema educacional que não confie nos seus especialistas disciplinares como fontes do conhecimento que devem estar nos currículos" (YOUNG, 2014, p. 199).

[...] a noção de currículo como prática desloca o foco para a ação coletiva dos sujeitos, de modo que as práticas dos professores tornam-se importantes ao desafiarem as concepções hegemônicas sobre conhecimento, no entanto salienta que se trata de uma ênfase enganadora (MACEDO, 2006, p. 103).

Segundo Macedo (2006), a corrente que se baseia na superação da concepção tradicional de currículo, ao salientar suas outras dimensões, como a dimensão política e prática, não conseguiu dar conta da superação da lógica 
tradicional. Verifica-se que há uma polarização que se alicerça na separação entre um momento de produção de documentos formais e outro(s) de sua implementação.

Nesta discussão consideram-se, também, dimensões do currículo e práticas educativas e a educação não formal. A educação formal, de acordo com Gohn (2006b), é aquela desenvolvida nas escolas, com conteúdos previamente demarcados. Para Gohn (2006b), a educação não formal, que para alguns é considerada informal, pode ser melhor descrita e analisada, pois capacita os indivíduos a se tornarem cidadãos do mundo, no mundo. Tem como objetivo o conhecimento sobre o mundo que perpassa os indivíduos e suas relações sociais. E, em cada campo, o agente do processo de construção do conhecimento é o professor.

\section{CULTURA, DIREITOS, O CURRÍCULO E A EDUCAÇÃO NÃO FORMAL}

Macedo (2006), ao se referir às ideias de Jung, considera que o currículo designa um conceito de que há um saber externo à escola a ser trabalhado via currículo. Assim, torna-se concreto um saber reificado como algo que deve ser ensinado.

Segundo a perspectiva da relação entre currículo e cultura, pode-se dizer que essa noção tem como base um conceito funcionalista, em que se vê o currículo e a escola como o lugar de transmissão da cultura (MACEDO, 2006).

As indagações sobre currículos não devem privilegiar apenas quais conhecimentos fazem parte do processo ensinar-aprender, mas também sua ordenação, organização, em que lógicas, hierarquias e precedências, quando e onde se dará o saber. Segundo Arroyo (2007), é necessário se pensar em que organização do trabalho estão dispostos os educandos, qual é a forma mais adequada para aprender e se formar. Para Arroyo, o ordenamento do currículo reproduz e legitima a visão que os docentes ou os gestores têm sobre os educandos, categorias e hierarquias como são classificados.

No entanto, ainda de acordo com Arroyo (2007), os educandos não são somente uma produção da escola, nem mesmo de um currículo, da docência ou de uma administração. Eles, quando chegam às escolas, carregam as imagens sociais com as quais os currículos, as escolas e docentes trabalham, reforçam ou a que se contrapõem. 
Chegam com identidades de classe, raça, etnia, gênero, território, campo, cidade, periferia... e sobre essas imagens construímos as imagens de alunos, definimos funções para cada escola e priorizamos ou secundarizamos conhecimentos, habilidades e competências. Se a escola e especificamente o ordenamento curricular são constituintes de protótipos de alunos, as imagens sociais que projetamos sobre eles nos chegam de fora, dadas pela cultura social, pela divisão de classes, pelas hierarquias sócio-étnico-raciais, de gênero e território, pela visão negativa que a sociedade tem das pessoas com "deficiências". O ordenamento curricular não é neutro, é condicionado por essa pluralidade de imagens sociais que nos chegam de fora (ARROYO, 2007, p. 23).

Essas considerações são pertinentes em uma discussão sobre a educação não formal, que ainda corresponde a uma área em construção. Para que haja um desenvolvimento, é necessária a participação de todos os atores da sociedade. Ao se considerar o sentido de ambiente, de onde se fala e quando se fala, a educação não formal é um conceito de educação que se adequa a várias situações do cotidiano antropológico. É uma ferramenta social que tem como finalidade a capacitação do indivíduo enquanto ser social e profissional (GOHN, 2003).

A educação não formal, parte significativa da pedagogia social, perpassa por diversas dimensões do processo educativo, de modo a possibilitar aos educandos uma compreensão de sua realidade, a fim de se entenderem como pessoas de direito, num ambiente de aprendizagem política. Segundo Gohn (2006a), a educação não formal, com estratégias pautadas em problemas cotidianos, procura facilitar o desenvolvimento e as potencialidades necessárias a partir de objetivos comunitários. Assim, pretende, com suas ações, o desenvolvimento e a apropriação do conceito de cidadania, ao transpor os conteúdos estabelecidos pelo ensino formal.

\section{PROJETOS TRANSVERSAIS, RESPONSABILIDADE SOCIAL NA INCLUSÃO E DESENVOLVIMENTOSOCIOECONÔMICO- AMBIENTAL}

A LDB n 9394/96, artigo 46, Inciso VII, dispõe que uma das finalidades da educação superior é a de "promover a extensão, aberta à participação da população, visando à difusão das conquistas e benefícios resultantes da criação cultural e da pesquisa científica e tecnológica geradas na instituição" (BRASIL, 1996). De acordo com a visão da Secretaria da Educação Superior do Ministério da Educação (BRASIL, 2016), a extensão é compreendida como um processo interdisciplinar, educativo, cultural, científico e político que promove uma 
interação entre a instituição de ensino superior e outros setores da sociedade. É um processo mediado pelos alunos de graduação orientados por um ou mais professores, segundo o princípio constitucional da indissociabilidade com o Ensino e a Pesquisa (BRASIL, 2016).

As discussões em sala de aula sobre a educação não formal e seu espaço no currículo, por meio dessas práticas de extensão, se basearam nas ideias de Gohn (2006b) e no estudo de Machado, Prados e Martino (2018), sobre práticas de extensão.

Assim, na instituição estadual de educação tecnológica estudada, as suas unidades de ensino superior elaboraram um Plano de Gestão que deveria conter um relatório das ações desenvolvidas na unidade, bem como um plano de ações para ser encaminhado à administração central dessa instituição. Foram elaborados pareceres, a partir do trabalho técnico de análise de tais Planos de Gestão, elaborados pela coordenadoria de projetos de tal instituição, divulgados por Machado; Prados e Martino (2018).

Foram relevantes as discussões em sala de aula, na disciplina Currículos e Programas, sobre o item do relatório das unidades de ensino: "Responsabilidade social na inclusão e desenvolvimento socioeconômico-ambiental", pelo seu compromisso com o exercício da cidadania. Segundo Machado; Prados e Martino (2018), foram descritos os projetos desenvolvidos nas unidades de ensino que se estendem para além dos muros da escola.

Nos relatórios das unidades de ensino, encaminhados à administração central, os projetos desenvolvidos foram descritos do seguinte modo:

- Projetos de inclusão: "Inclusão Digital para a Melhor Idade", desenvolvido por alunos e seu professor, oferecido à comunidade uma vez por semana para 20 (vinte) pessoas da $3^{a}$ idade da comunidade que nunca tiveram contato com o computador, ao longo de um semestre letivo; "Projeto Inclusão Digital e Noções de Cidadania"; "Projeto Capacitação Tecnológica", para o ingresso de alunos especiais em disciplinas específicas de algum curso de graduação, desenvolvido por alunos e um professor responsável, oferecido à comunidade semanalmente; "Projeto Ler e Escrever", desenvolvido por um professor de Língua Portuguesa e dois estudantes, também oferecido à comunidade para pessoas carentes, semestralmente.

- Cursos: "Curso de Conversação Básica em Inglês", desenvolvido por um professor de Língua Inglesa e oferecido à comunidade, semestralmente;

- Projetos de sustentabilidade: "Coleta de Lacres; de Pilhas, Baterias e Lixo eletrônico"; "Projeto Ações de Educação Ambiental" - parceria com a ONG Olho D’Água; “Projeto Informe-se e Cuide-se”. São projetos relevantes que impactam no entorno de uma Faculdade de Tecnologia, nos quais se destaca, também, a preocupação com práticas sustentáveis. 
O sentimento comunitário, trazido pela educação não formal, carrega como objetivo central a organização do conhecimento de forma comunitária, expondo um melhor entendimento e esclarecimento de mundo, tanto para educadores como para educandos, para compreender o que passa ao seu redor (GOHN, 2013). Todo o trabalho da educação não formal vem de campanhas de conscientização, projetos sociais. É importante salientar que tudo isso será feito sem a chancela de documentos que atestem a formalização daquele ato.

Essa educação, como um direito humano, contribui para a formação e para o desenvolvimento da personalidade dos indivíduos, para o fortalecimento dos direitos e da liberdade e para uma cultura universal de direitos humanos. Essa formação cidadã supõe práticas que possibilitem que as pessoas sejam conscientes de seus direitos e deveres e, em consequência disso, tenham uma atuação protagonista na sociedade. Assim, entende-se que a cidadania não pode ser concebida como um processo passivo, mas que pressupõe o direito de ter direito e seu poder de exercício (GOHN, 2013).

Para Gohn (2003), a educação não formal tem um caráter coletivo e passa por um processo de ação de um grupo, de modo que é vivida como práxis concreta em conjunto, nas práticas sociais, ainda que o resultado do que se aprende seja absorvido individualmente. Tal estratégia de difusão de conhecimentos estabelecese em uma dimensão social, sendo possível que os indivíduos se organizem com objetivos voltados para a solução de problemas coletivos.

Assim, é importante o trabalho com a educação nãoformal em bairros depreciados e sem sentimento de pertencimento social, como comunidades carentes. Gohn (2006a) apresenta algumas características que podem gerar metas, processos planejados de ações envolvendo a educação não formal: o aprendizado das diferenças; aprende-se a conviver com os demais; socializa-se o respeito mútuo; adaptação do grupo a diferentes culturas, ao se reconhecer os indivíduos e o papel do outro; construção da identidade coletiva de um grupo; e o balizamento de regras éticas relativas às condutas aceitáveis socialmente.

Certas ações podem sim se apresentar no ambiente da educação formal, como por exemplo, em complementação a carga de escolas que ofertam o período integral, porém, tudo depende da interação e participação da comunidade na escola e sua intervenção para que os colegiados reflitam suas práticas e não tornem o ambiente educacional com educação formal uma inclusão excludente.

Em síntese, no estudo de Machado, Prados e Martino (2018), pôde-se perceber o protagonismo docente em trinta e cinco (35) ações, mas em vinte e três (23) casos não foi possível definir a responsabilidade pela ação nos Planos 
de Gestão. Nesse caso, caracteriza-se o protagonismo do estudante de ensino superior tecnológico por meio da mobilização do conhecimento para fins de transformação qualificada da realidade.

Para Machado, Prados e Martino (2018), as ações de responsabilidade social, desenvolvidas na instituição estadual estudada, possuem vários focos, que vão desde formação cidadã, meio ambiente (por exemplo, recomposição ambiental e empreendedorismo socioambiental), juventude em situação de vulnerabilidade, população idosa, mulheres, coletivos, comunidade próxima, entre outros.

\section{CONSIDERAÇÕES FINAIS}

Nas discussões propostas nas aulas da disciplina Currículos e Programas, pôde-se explicitar conceitos acerca da perspectiva técnica da organização do currículo e da dimensão cultural e política para a formação dos educandos.

Nos cursos superiores de tecnologia, caracteriza-se uma visão dos alunos como aspirantes ao mercado de trabalho, que é determinante para os formuladores de políticas de currículo no ensino técnico e tecnológico. As reorientações curriculares atendem a novas exigências que o mundo do trabalho impõe aos jovens. As demandas do mercado, da sociedade, da ciência, das tecnologias e competências, ou a sociedade da informática, ainda são os referenciais para o que se ensinar e o que se aprender.

Acredita-se que o desafio da escola, hoje, é conciliar a prática social e a prática acadêmica, pois os estudantes reconhecem, ou devem reconhecer, as teorias em suas práticas sociais cotidianas, a fim de integrar conhecimentos que antes se aplicavam separadamente aos contextos escolares e extraescolares.

A fim de fomentar discussões e intervenções de docentes, quanto às práticas na educação profissional, para ampliar novos espaços de aprendizagem, as contribuições da linha da pedagogia social, quanto à educação não formal, foram relevantes. No que se refere às contribuições da perspectiva da educação profissional, verificou-se que os mestrandos procuram não se prender apenas ao conteúdo formalizado sobre currículo, segundo a concepção formal e tradicional, mas também aos saberes compartilhados por todos, configurando-se nas práticas educacionais a responsabilidade social.

Esta análise, realizada a partir da descrição de projetos desenvolvidos nas unidades de ensino superior da instituição estudada, que apresentam características da educação não formal, quanto aos objetivos, ambiente e coletividade, possibilitou o aprofundamento das discussões sobre o currículo. Pretendeu-se ampliar o conhecimento sobre formação, políticas e cultura, de forma a possibilitar não 
apenas uma reflexão sobre a educação profissional, mas também o conhecimento sobre as discussões contemporâneas, sobre responsabilidade social e educação não formal.

\section{REFERÊNCIAS}

ARROYO, Miguel Gonzáles. Educandos e Educadores: seus Direitos e o Currículo. Ministério da Educação Secretaria de Educação Básica. Brasília: Ministério da Educação, Secretaria de Educação Básica, 2007. 56p.

BRASIL. Sistema Nacional de Avaliação da Educação Superior - SINAES. Lei $\mathbf{N}^{\mathbf{0}}$ 10.861, de 14 de abril de 2004. Disponível em: http://www.planalto.gov.br/ ccivil_03/_ato2004-2006/2004/lei/110.861.htm. Acesso em 10 abr. 2020.

BRASIL. Ministério da Educação. Secretaria da Educação Superior. Edital PROEXT, 2016. Programa de Apoio à Extensão Universitária MEC/SESu. Disponível em: http://portal.mec.gov.br/index.php?option=com_content\&vie $\mathrm{w}=$ article\&id=12243: editais\&catid=235\&Itemid=164. Acesso em: $11 \mathrm{abr} .2020$.

BURKE, Peter. Uma história social do conhecimento. De Gutenberg a Diderot. Rio de Janeiro: Jorge Zahar Ed, 2003.

GOHN, M. G. Conselhos gestores e participação sociopolítica. 2. ed. São Paulo: Cortez, 2003.

GOHN, M. G. Educação não-formal na pedagogia social. In: I Congresso Internacional de Pedagogia Social, 1, 2006a. Faculdade de Educação, Universidade de São Paulo, Disponível em: http://www.proceedings.scielo.br/ scielo.php?script $=$ sci_arttext\&pid=MSC0000000092006000100034\&lng=en\&nr $\mathrm{m}=$ abn. Acesso em: 11 abr. 2020.

GOHN, M. G. Educação não-formal, participação da sociedade civil e estruturas colegiadas nas escolas. Ensaio: aval. pol. públ. Educ., Rio de Janeiro, v.14, n.50, p. 27-38, jan./mar. 2006b. Disponível em: http://escoladegestores.mec.gov.br/ site/8-biblioteca/pdf/30405.pdf. Acesso em: 10 abr. 2020. 
GOHN, M. G. Desafios dos movimentos sociais hoje no Brasil. SER social, Brasília, v.15, n. 33, p261-384, jul. / dez. 2013. Disponível em: http://periodicos. unb.br/index.php/SER_Social/article/view/9519/7598. Acesso em: 10 abr. 2020.

MACEDO, E. Currículo: Política, Cultura e Poder. Elisabete Macedo Universidade do Estado do Rio de Janeiro. Currículo sem Fronteiras, v.6, n.2, pp.98-113, Jul/Dez 2006.

MACHADO, M.M; PRADOS, R. M. N. MARTINO, M. A. A extensão e a Educação Profissional e Tecnológica no Centro Paula Souza: realizações, desafios e oportunidades. In: FREIRE, E. VERONA, J. A; BATISTA, S. S. S. (orgs) Educação Profissional e Tecnológica, Extensão e Cultura. Jundiaí, SP: Paco Editorial, 2018. Disponível em: https://www.researchgate. net/publication/325576322_A_Extensao_e_a_Educacao_Profissional_e_ Tecnologica_no_Centro_Paula_Souza_realizacoes_desafios_e_oportunidades Acesso em 12 abr. 2020.

SANTOS, B. S. A universidade no século XXI: para uma reforma democrática e emancipatória da universidade. 3. ed. São Paulo: Cortez, 2011.

SÃo PAUlO. Portaria CEETEPS/CESU, 01 de 20 de setembro de 2013. Disponível em: http://www.radaroficial.com.br/d/4529405804150784. Acesso em 10 abr. 2020.

SACRISTÁN, J.G. O que significa o currículo? In: SACRISTAN, José Gimeno (org). Saberes e Incertezas sobre o Currículo. Porto Alegre: editora Penso, 2013.

SCHMIDT, Elisabeth Silveira. Currículo: Uma abordagem conceitual e histórica. In: Revista Publicatio. UEPG. Ciências Humanas, Linguística, Letras e Artes. V 11, n. 1, 2003. Disponível em: http://www.revistas2.uepg.br/index. php/humanas/article/view/492.

TEDESCO, J. C. EL Nuevo Pacto Educativo. Educación, Competitividad y Ciudadanía Em La Sociedad Moderna. Madrid: Grupo Anaya, S.A., 1995. 
TEDESCO, J. C. Fenômenos de segregação e exclusão social na sociedade do conhecimento. In: Cadernos de Pesquisa. No 117, p. 13-28, nov/ 2002. Disponível em: http://www.scielo.br/scielo.php?pid=S010015742002000300002\&script=sci_abstract \&tlng=pt. Acesso em: 22 abr. 2020.

YOUNG, Michael. Teoria do Currículo: o que é e por que é importante? In: Cadernos de Pesquisa. Vol. 44 N. 151, p. 190-202, jan. /mar. 2014. Disponível em: http://www.scielo.br/pdf/cp/v44n151/10.pdf. Acesso em: 10 abr. 2020.

\begin{abstract}
Maria Cecília de Souza Minayo
Pesquisadora Emérita CNPq. Possui graduação em Sociologia pela Universidade Federal do Rio de Janeiro (1978), graduação em Ciências Sociais - City University of New York (1979), mestrado em Antropologia Social pela Universidade Federal do Rio de Janeiro (1985) e doutorado em Saúde Pública pela Fundação Oswaldo Cruz (1989). Desde 1997 é editora científica da revista Ciência \& Saúde coletiva da Associação Brasileira de Saúde Coletiva e pesquisadora titular da Fundação Oswaldo Cruz. Tem experiência na área de Saúde Pública, com ênfase em Saúde Coletiva, atuando como professora, pesquisadora e orientadora principalmente nos seguintes temas: metodologia de pesquisa social, metodologia da pesquisa social em saúde pública, violência e saúde, causas externas, violência, violência autoinfligida, saúde coletiva e saúde e sociedade. E-mail: mminayo@gmail.com
\end{abstract}

\title{
Pedro Demo
}

Possui graduação em Filosofia - Bom Jesus (1963) e doutorado em Sociologia - Universität Des Saarlandes/Alemanha (1971). Professor titular aposentado da Universidade de Brasília, Departamento de Sociologia. Professor Emérito. Fez pós-doutorado na UCLA/Los Angeles (1999-2000). Tem experiência na área de Política Social, com ênfase em Sociologia da Educação e Pobreza Política. Trabalha com Metodologia Científica, no contexto da Teoria Crítica e Pesquisa Qualitativa. Pesquisa principalmente a questão da aprendizagem nas escolas públicas, por conta dos desafios da cidadania popular. Publicou mais de 90 livros. E-mail: pedrodemo@uol.com.br 


\section{Renan Antônio da Silva}

Pós - Doutor em Educação pela Universidade Federal do Rio Grande do Norte (UFRN). Pós - Doutor em Ciências Sociais (2019) pela Universidade Estadual Paulista (UNESP/ Marília). Docente Permanente no Programa de Pós-Graduação em Políticas Públicas (PPG-PP) da Universidade de Mogi das Cruzes (UMC) com bolsa PNPD/CAPES. Doutor em Educação Escolar (2018) pela Universidade Estadual Paulista (UNESP/ Araraquara). Realizou o Estágio Doutoral (Doutorado Sanduíche) com bolsa CAPES/PDSE, junto ao Centro em Investigação Social (CIS) pelo Instituto Universitário de Lisboa - ISCTE - Portugal (2015-2016).Consultor no United Nations Educational, Scientific, and Cultural Organization (UNESCO). Associado Profissional nos cursos de MBA da ESALQ/USP. Pesquisador no Departamento de Pesquisa do Centro Universitário do Sul de Minas - UNIS. E-mail: r.silva@unesp.br

Recebido em 16/04/2020

Aprovado em 01/07/2020 